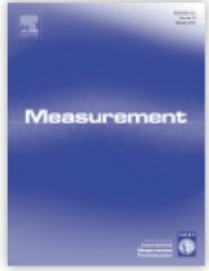

ISSN: $0263-2241$

\section{Submit Your Paper}

\section{View Articles}

\section{Guide for Authors}

$\checkmark$

Abstracting/ Indexing

Track Your Paper

\section{Order Journal}

Sample Issue $\pi$

\section{Journal Metrics \\ CiteScore: $\mathbf{2 . 5 2}$ (1) \\ More about CiteScore \\ Impact Factor: 2.359 (i) \\ 5-Year Impact Factor: 2.255 (i) \\ Source Normalized Impact per Paper (SNIP): 1.630 (1) \\ SCImago Journal Rank (SJR): 0.734 (i) \\ $>$ View More on Journal Insights $\lambda$}

\section{Article Enrichments $\quad \vee$ \\ $>$ AudioSlides \\ $>$ Data in Brief co-submission \\ > Interactive MATLAB Figure Viewer}

Related Links 주

$>$ Author Stats $\pi$ (1)

> Publishing Campus $\pi$

$>$ Author Services

$>$ Try out personalized alert features

\section{Measurement}

Journal of the International Measurement Confederation (IMEKO $x$ )

$>$ Supports Open Access

Editor-in-Chief: K.T.V. Grattan

$>$ View Editorial Board

Contributions are invited on all aspects of the research, development and applications of the science and technology of measurement and

instrumentation. Authors are encouraged to submit novel material which could include results of research or experimental work, may deal with practical developments related...

Read more

\section{Most Downloaded Recent Articles Most Cited Open Access Articles}

Measuring risk-aversion: The challenge $\pi$ P.J. Thomas

Early fault diagnosis of bearing and stator faults of the single-phase induction motor using acoustic signals $\pi$ Adam Glowacz $\mid$ Witold Glowacz $\mid . .$.

Optical flow background estimation for real-time pan/tilt camera object tracking $\pi$ Daniel D. Doyle $\mid$ Alan L. Jennings $\mid \ldots$

View All Articles >

\section{Announcements}

Heliyon Partner Journal त

This journal is now partnering with Heliyon, an open access journal from Elsevier publishing quality peer reviewed research across all disciplines. Partner journals provide authors with an easy route to transfer their research to Heliyon.

>Learn more at Heliyon.com >

$>$ View All

Videos - Audioslides

Videos - Audioslides

Automatic Detection of Onset and Offset of QRS Complexes Independent of Isoelectric Segments

Bearing defect inspection based on machine vision

Measurement and statistical analysis toward reproducibility validation of $\mathrm{AZ}_{45} \mathrm{G}_{2}$ cylindrical microlenses obtained by reflow

\section{$>$ View All}

News

Signal Processing and Control Digital Catalogue 2017

Hear it from the authors: new video commentary!

$>$ View All 
Home > Journals > Measurement > Editorial Board

\section{Submit Your Paper $\quad \checkmark$}

View Articles $\pi$

Guide for Authors

Abstracting/ Indexing

Track Your Paper

Order Journal

Sample Issue $\pi$

Journal Metrics

CiteScore: 2.52 (1)

More about CiteScore

Impact Factor: 2.359

5-Year Impact Factor: 2.255 (1)

Source Normalized Impact per Paper

(SNIP): $1.630 \odot$

SCImago Journal Rank (SJR): 0.734 (

$>$ View More on Journal Insights

Article Enrichments

$>$ Audioslides

Data in Brief co-submission

$>$ Interactive MATLAB Figure Viewer

Related Links

Author Stats $\approx$ (1)

> Publishing Campus ?

$>$ Author Services

$>$ Try out personalized alert features

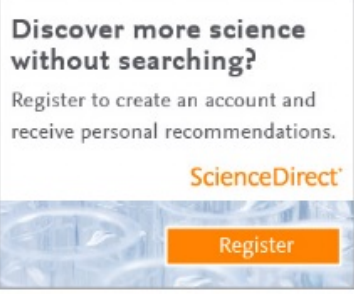

\section{Measurement Editorial Board}

Editor-in-Chief

K.T.V. Grattan

City, University of London, London, UK

Associate Editors

S. Khan

City, University of London, London, England, UK

T. Sun

City, University of London, London, UK

T. Sarkodie-Gyan

University of Texas, El Paso, Texas, USA

A. Lay-Ekuakille

University of Salento, Lecce, Italy

Membership of the Board

S. Bennett

National Physical Laboratory, Teddington, Middlesex, UK

N. Fox

National Physical Laboratory, Teddington, Middlesex, UK

R.Z. Morawski

Warsaw University of Technology, Warsaw, Poland

P.H. Osanna

Technische Universität Wien, Wien, Austria

A. Wallard

National Physical Laboratory, Teddington, Middlesex, UK

Ex-Officio Membership of the Board

G.W. Bahng

Korea Research Institute of Standards and Science, Daejeon, The Republic of Korea

L. Borbas

Budapest University of Technology and Economics, Budapest, Hungary

M. Borsic

Croatian Metrology Society, Zagreb, Croatia

T. Bruns

Physikalisch-Technische Bundesanstalt, Braunschweig, Germany 
P. Daponte

Università degli Studi del Sannio, Benevento, Italy

C. Ferrero

INRIM National Inst. Searches Metrologica, Torino, Italy

J. Holub

Czech Technical University in Prague (Ceské Vysolké Ucení Technické), Prague, Czech Republic

D.I. Kang

KRISS, Taejon, , The Republic of Korea

\section{P. Kneppo}

Czech Technical University in Prague (Ceské Vysoké Ucení Technické), Czech Republic

Y. Koike

Tokyo Institute of Technology, Midori-ku, Yokohama, Japan

\section{R. Kumme}

Physikalisch-Technische Bundesanstalt, Braunschweig, Germany

L. Mari

CETIC, Castellanza (VA), Italy

L. Michaeli

Technical University Kosice, Kosice, Slovakia

L. Monostori

Hungarian Academy of Sciences, Budapest, Hungary

F. Pavese

Istituto Nazionale di Ricerca Metrologica (INRIM), Torino, Italy

\section{T. Pfeifer}

RWTH Aachen University (RWTH), Aachen, Germany

M. Reader-Harris

National Engineering Lab, East Kilbride, Glasgow, UK

P.L. Regtien

University of Twente, Enschede, Netherlands

F. Righini

INRIM National Inst. Searches Metrologica, Torino, Italy

P.M.B. Silva Girāo

Portugal

K.D. Sommer

Physikalisch-Technische Bundesanstalt, Braunschweig, Germany

S. Tachi

University of Tokyo, Tokyo, Japan

J.C. Torres Guzmán

Centro Nacional de Metrologia - CENAM, Querétaro, Mexico

A. Weckenmann

Friedrich-Alexander-Universität Erlangen-Nürnberg, Erlangen, Germany 
ADVERTISEMENT

Winner of the PROSE Award
for Innovation in Journal Publishing
SoftwareX

\begin{tabular}{|c|c|c|c|c|c|}
\hline ScienceDir & Journ & Books & & & opping \\
\hline \multicolumn{2}{|l|}{ Search all fields } & Author name & --This Journal/Book-- & Volume & Issue \\
\hline \multirow{3}{*}{ sit } & \multicolumn{5}{|l|}{ Measurement } \\
\hline & Supports Open Access & About this Journal & Sample Issue Online & \multicolumn{2}{|c|}{ Submit your Article } \\
\hline & \multicolumn{5}{|c|}{ Incorporating Industrial Metrology; } \\
\hline \multirow{3}{*}{ Measurement } & \multicolumn{5}{|c|}{ வ Get new article feed } \\
\hline & \multicolumn{5}{|c|}{ ه Get new Open Access article feed } \\
\hline & \multicolumn{5}{|c|}{ L Subscribe to new volume alerts } \\
\hline 를 & \multicolumn{5}{|c|}{$\begin{array}{l}\text { III Add to Favorites } \\
\text { Copyright } \odot 2016 \text { Elsevier Ltd. All rights reserved }\end{array}$} \\
\hline
\end{tabular}

\begin{tabular}{l|l}
$<$ Previous vol/iss $\mid$ Next vol/iss $>$ \\
.
\end{tabular}

\section{Articles in Press}

Open Access articles

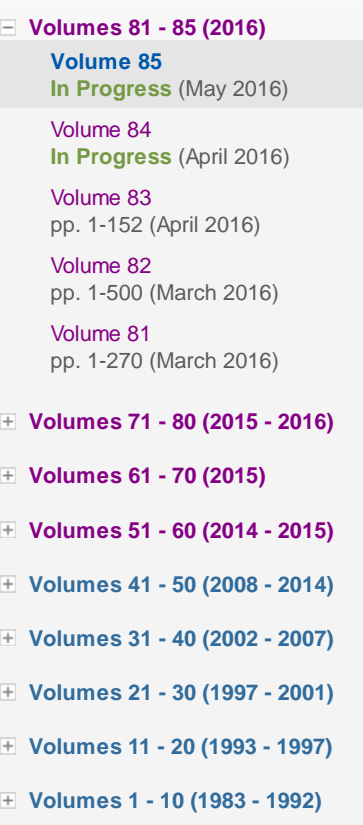

† * Purchase || Download PDFs $\quad$ All access types .

\section{Export =}

This issue is In Progress but contains articles that are final and fully citable. For recently accepted articles, see Articles in Press.

$\square$ Algorithm for measuring gears implemented with general-purpose spreadsheet software Original Research Article

Pages 1-12

C. García-Hernández, R. Gella-Marín, J.L. Huertas-Talón, L. Berges-Muro

I Abstract $\mid$ Close graphical abstract | I Research highlights $\Rightarrow$ Purchase PDF

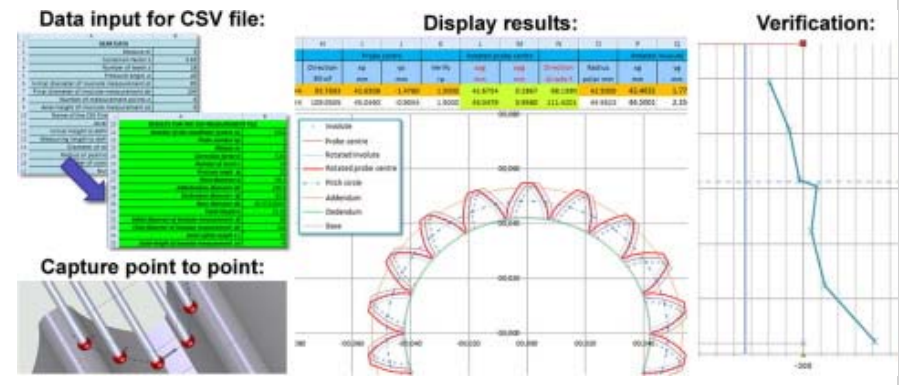

$\square$ Reliability and sensitivity of a novel dynamic balance test for alpine skiers Original Research Article

Pages 13-19

Andrej Panjan, Matej Supej, Jernej Rosker, Nejc Sarabon

I Abstract $\mid$ Close research highlights $\Rightarrow$ Purchase PDF

\section{Highlights}

ELSEVIER

- Novel dynamic balance test is sensitive to alpine skier's expertise level.

- Application of cross correlation method for analysing rhythmic COP movements.

- Trained alpine skiers present superior balance with an additional loading.

- Trained alpine skiers are more accurate in controlling lateral COM shift.

$\square$ Vibration signal modeling of a planetary gear set with transmission path effect analysis Original Research Article

Pages 20-31

Libin Liu, Xihui Liang, Ming J. Zuo

I Abstract $\mid$ Close research highlights $\neq$ Purchase PDF

\section{Highlights}

- A comprehensive vibration signal model for a planetary gear set is proposed.

- Result ant vibration includes sources from sun gear, ring gear, and planet gears.

- Transmission path contains two parts: inside the gearbox and along the casing.

- Vibration amplitude is a function of the relative length of the transmission path.

$\square$ Implementation of ANN-based Selective Harmonic Elimination PWM using Hybrid Genetic Algorithm-based optimization Original Research Article Pages 32-42

Erkan Deniz, Omur Aydogmus, Zafer Aydogmus 
$\square$ 3D measuring and segmentation method for hot heavy forging Original Research Article

Pages 43-53

Zhengchun Du, Zhaoyong Wu, Jianguo Yang

I Abstract . Close research highlights

Purchase PDF

\section{Highlights}

- We describe a method for measuring the dimensions of hot heavy forgings.

- A sequence of 2D laser scans generates a point cloud dataset.

- The item of interest is isolated from the background via cluster analysis among other techniques.

- The processed dataset can yield accurate three dimensional measurements.

- This process has been experimentally verified in the laboratory and the workshop.

$\square$ Design and modeling of an intelligent temperature to frequency converter Original Research Article

Pages 54-64

Naveen Kumar Vaegae, Venkata Lakshmi Narayana Komanapalli, Bhujanga Rao Annepu

I Abstract a Close research highlights $\Rightarrow$ Purchase PDF

\section{Highlights}

- Modeling of intelligent temperature to frequency converter using thermistor.

- Hybrid technique is developed with improved linearity and sensitivity.

- Levenberg-Marquardt algorithm trains multilayer perceptron neural network.

- Implementation of ANN modeling uses ATmega 328 microcontroller unit.

$\square$ Cutting force analysis to estimate the friction force in linear guideways of CNC machine Original Research Article

Pages 65-79

Mahdi Sparham, Ahmed A.D. Sarhan, N.A. Mardi, M. Dahari, M. Hamdi

I Abstract $\mid$ Close research highlights $\Rightarrow$ Purchase PDF

\section{Highlights}

- Guideways are significant parts in CNC machines to yield precision and accuracy.

- Friction in guideways is a major factor that prevents more accuracy and precision.

- $\quad$ The friction forces are modeled using the analyzed cutting forces on guideways.

- Coefficient of frictions are measured experimentally at dry lubrication condition.

- The friction force is estimated using the identified coefficient of friction.

$\square$ Application of two-output port fiber coupler as gasoline level sensor Original Research Article

Pages 80-87

Samian, Y.G.Y. Yhuwana, A.H. Zaidan, Supadi, Sujito

I Abstract $\mid$ Close research highlights

* Purchase PDF

\section{Highlights}

- New method to detect gasoline level using two probes from single fiber coupler.

- The sensor mechanism is simple which is based on hydrostatics pressure principle.

- Results show working range increase two fold compare to sensor using single probe. 
Home Journal Rankings Country Rankings Viz Tools Help About Us

\section{Measurement: Journal of the International Measurement Confederation}

\author{
Country Netherlands \\ Subject Area and \\ Category \\ Publisher \\ Publication type \\ ISSN \\ Coverage
}

Scope

Contributions are invited on all aspects of the research, development and applications of the science and technology of measurement and instrumentation. Authors are encouraged to submit novel material which could include results of research or experimental work, may deal with practical developments related to plant or process, discuss new developments in sensors and instrumentation, or relate to systems evaluation and modelling. Topics covered include: General principles of measurement and instrumentation; Sensors and sensor systems: design and evaluation; Data acquisition; Signal transmission; Processing and evaluation; Data output; Systems aspects; Systems modelling and evaluation; Specific applications in measurement and instrumentation. (source)

\section{Quartiles}

Applied Mathematics

Condensed Matter Physics

Education

Statistics and Probability

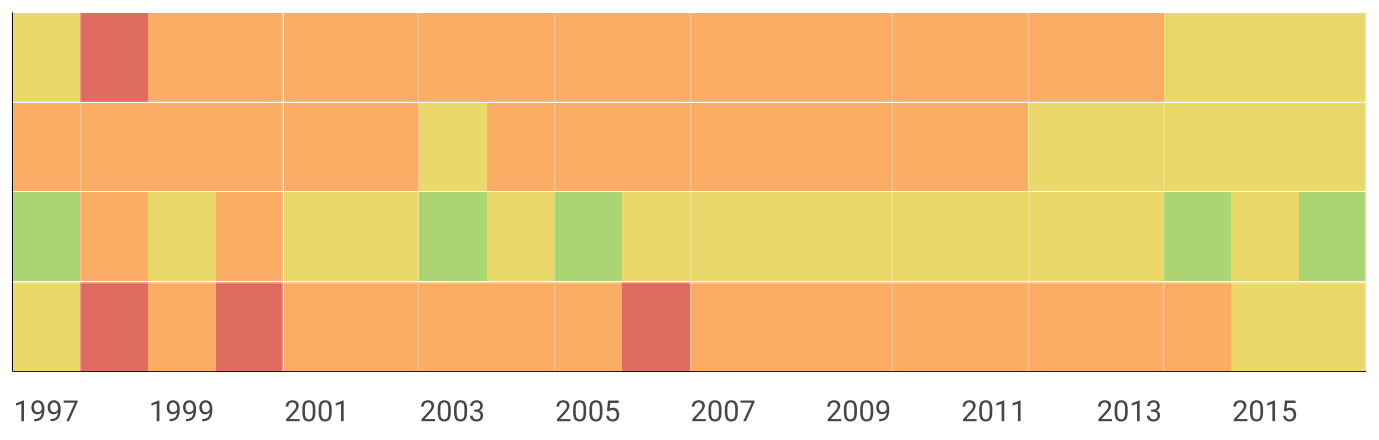



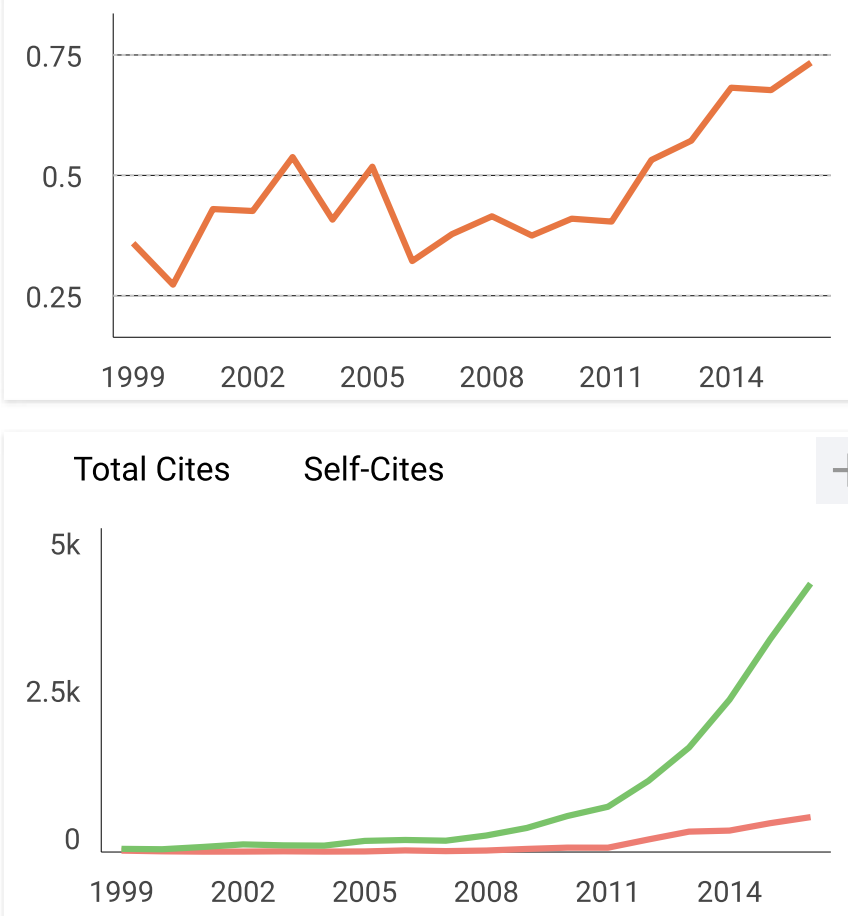

\section{External Cites per Doc Cites per Doc}

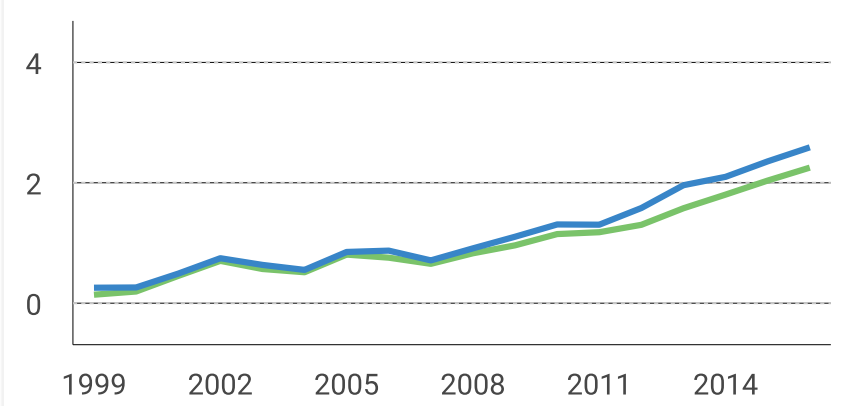

Citable documents Non-citable documents $\quad+$

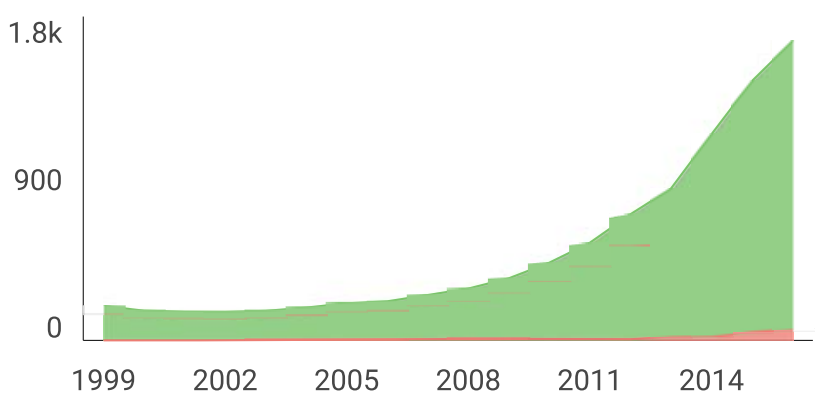

$\leftarrow$ Show this widget in your own website

Just copy the code below and paste within your html code:

$<a$ href="http://www.scimagr

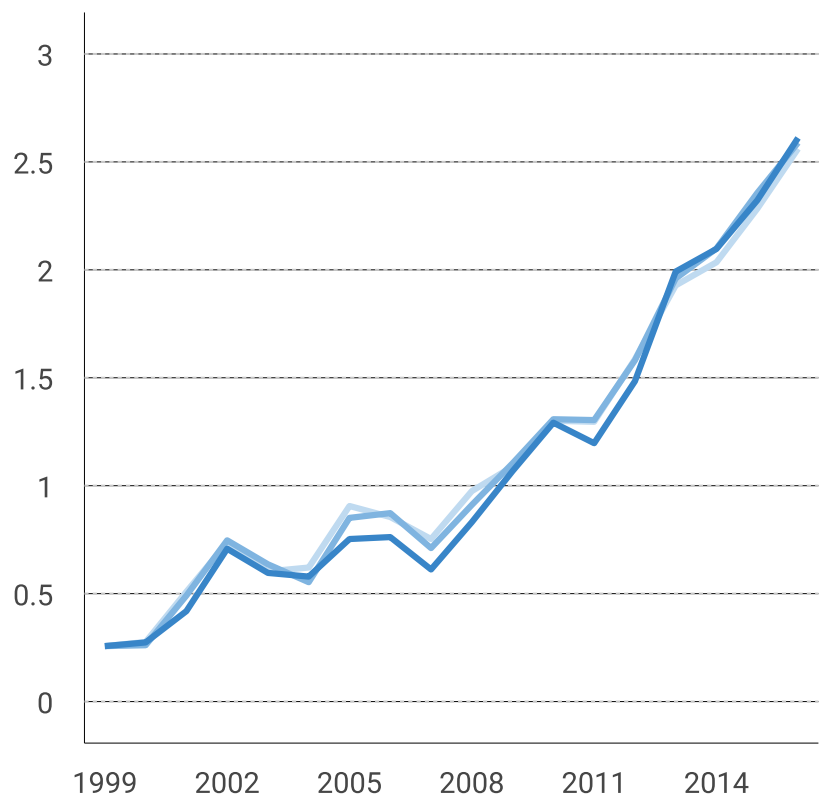

Cites / Doc. (4 years)

Cites / Doc. (3 years)

Cites / Doc. (2 years)

\section{\% International Collaboration}

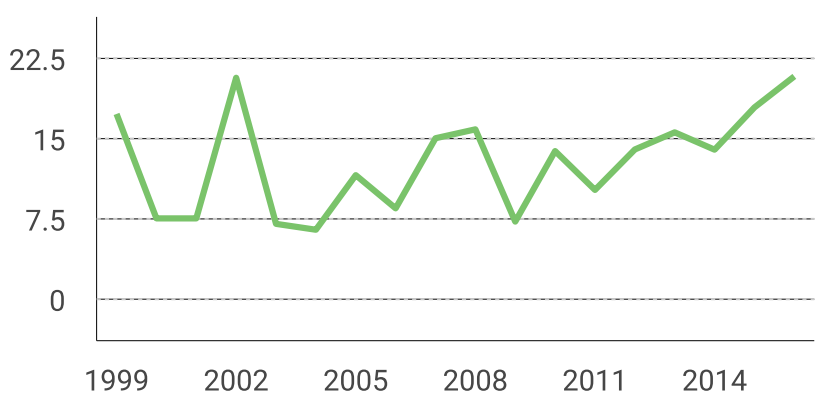

Cited documents Uncited documents

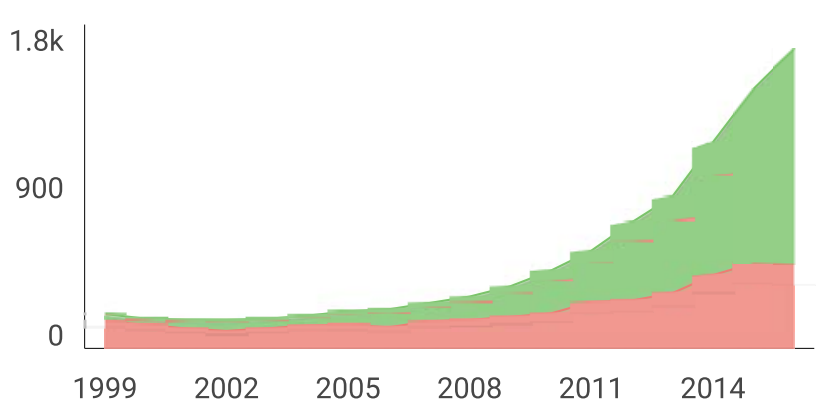




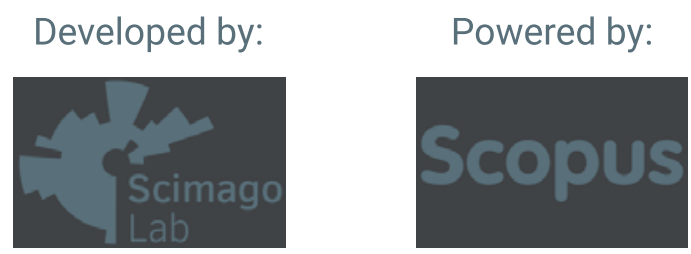

Follow us on Twitter

Scimago Lab, Copyright 2007-2017. Data Source: Scopus ${ }^{\circledR}$ 


\title{
Application of two-output port fiber coupler as gasoline level sensor
}

\author{
Samian $^{\text {a,* }}$, Y.G.Y. Yhuwana ${ }^{\text {a }}$, A.H. Zaidan ${ }^{\text {a }}$, Supadi ${ }^{\text {a }}$, Sujito ${ }^{\text {b }}$ \\ a Physics Department, Faculty of Science and Technology, Universitas Airlangga, Surabaya, Indonesia \\ ${ }^{\mathrm{b}}$ Physics Department, Faculty of Mathematics and Science, The State University of Malang, Malang, Indonesia
}

\section{A R T I C L E I N F O}

\section{Article history:}

Received 17 April 2015

Received in revised form 29 October 2015

Accepted 16 February 2016

Available online 21 February 2016

\section{Keywords:}

Gasoline level sensor

Sensing port fiber coupler

RDD

Probe

Hydrostatic pressure

\begin{abstract}
A B S T R A C T
Detection of gasoline level can be done in a safe and simple way using two output port multimode fiber coupler with a structure of $2 \times 2$ as a sensor. Two output ports (sensing port) are connected with two reflector displacement device (RDD) and functioned as two probes. These probes are placed on the wall of gasoline tank in a storied and work interchangeably or together depending on setting of these probes. Detection mechanism of the system is based on changes in intensity of reflected light from the reflector RDD that shifts due to changes in level of gasoline (hydrostatic pressure principle). Changes in intensity of light coming into the sensing port are then forwarded to the optical detector. Experiments performed by varying the location of the second probe as $45 \mathrm{~cm}, 50 \mathrm{~cm}$, and $55 \mathrm{~cm}$ above the first probe to detect the level of gasoline in the process of filling and emptying the tank. Experimental results show the process of filling and emptying the tank have small differences of $6 \%$ with the dynamic range, the linear region, and resolution are $100 \mathrm{~cm}, 70 \mathrm{~cm}$, and $0.4 \mathrm{~cm}$ respectively. Sensor sensitivity in filling and emptying process of the tank are $2.7 \mathrm{mV} / \mathrm{cm}$ and $2.8 \mathrm{mV} / \mathrm{cm}$ respectively. These results were the best performance of the sensor, which occurs when the level of the second probe was $55 \mathrm{~cm}$ above the first probe.
\end{abstract}

(c) 2016 Elsevier Ltd. All rights reserved.

\section{Introduction}

Detection of liquid level using optical fiber (optical fiber liquid level sensors) can be done in two methods, i.e. direct and indirect contact between the optical fiber with liquid. The second method can use other devices as a probe or utilizes change in the trajectory of light due to changes in liquid level. For the first method, direct contact between optical fiber with liquid can be made using polished plastic optical fiber [1], spiral side-emitting optical fiber [2], as well as the use of long period fiber grating [3]. All three use the principle side-emitting optical fiber. The use of a Prism as a probe that is connected with optical fiber [4],

\footnotetext{
* Corresponding author.

E-mail address: samian@fst.unair.ac.id ( Samian).
}

the float is connected to the cantilever which contained fiber Bragg grating [5], the lever (have buoyancy) connected with fiber interferometer [6], the system of membranes and reflectors (RDD) connected with fiber coupler [7] is an indirect contact method between fiber optic with liquid.

The types of liquid that will be detected affect the selection of fiber optics and detection method. For gasoline, safe from risk of fire and explosion during operation is a major consideration in addition to accuracy and lifetime of the sensor. A sensor with these criteria was demonstrated has been able to detect the level of gasoline using a single output port plastic fiber coupler (fiber with a structure of $2 \times 2$ ). One of the output ports is paired with a reflector displacement device (RDD) and serves as a probe. RDD comprises a reflector Board that is attached to the 
membrane at the bottom of the tank. The sensing principle is to detect displacement of reflector, which is attached to the membrane, due to the change of gasoline hydrostatic pressure. The displacement of reflector can be detected using fiber coupler from the change of optical power light reflected by the reflector. The results obtained are dynamic range and sensors linear region, which are $180 \mathrm{~cm}$ and $40 \mathrm{~cm}$ respectively [7]. The linear region of the sensor, a working range of the sensor, are still far from industrial needs that require the detection of gasoline or fuel level.
In this paper, efforts to increase linear region of the sensor will be described by optimizing both the output port of fiber coupler with RDD (the probe) to detect the level of gasoline in multilevel way.

\section{Sensors design and operating principle}

Fig. 1 shows the design of gasoline level sensor using two probes. Fig. 1(a) shows the gasoline level detection mechanism using two probes. The first probe was formed

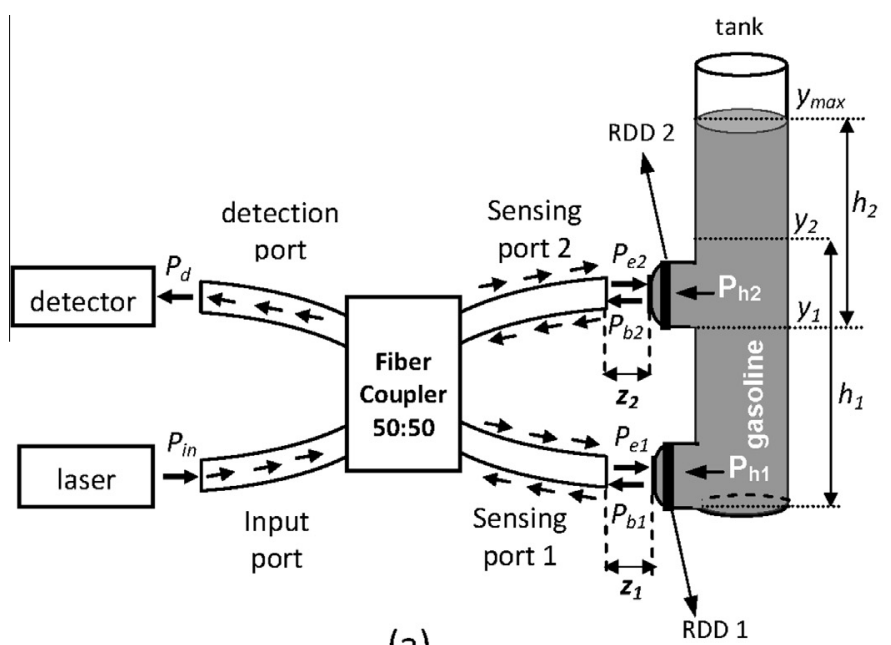

(a)

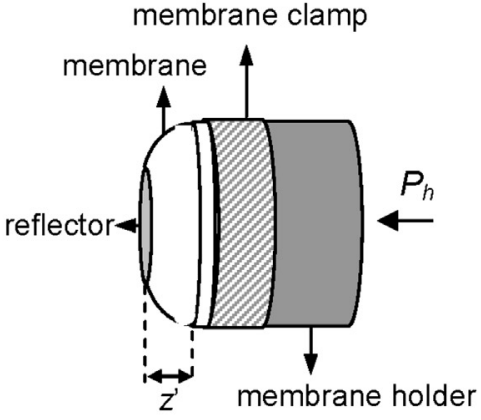

(b)

Fig. 1. (a) Sensor design and (b) reflector displacement device (RDD).

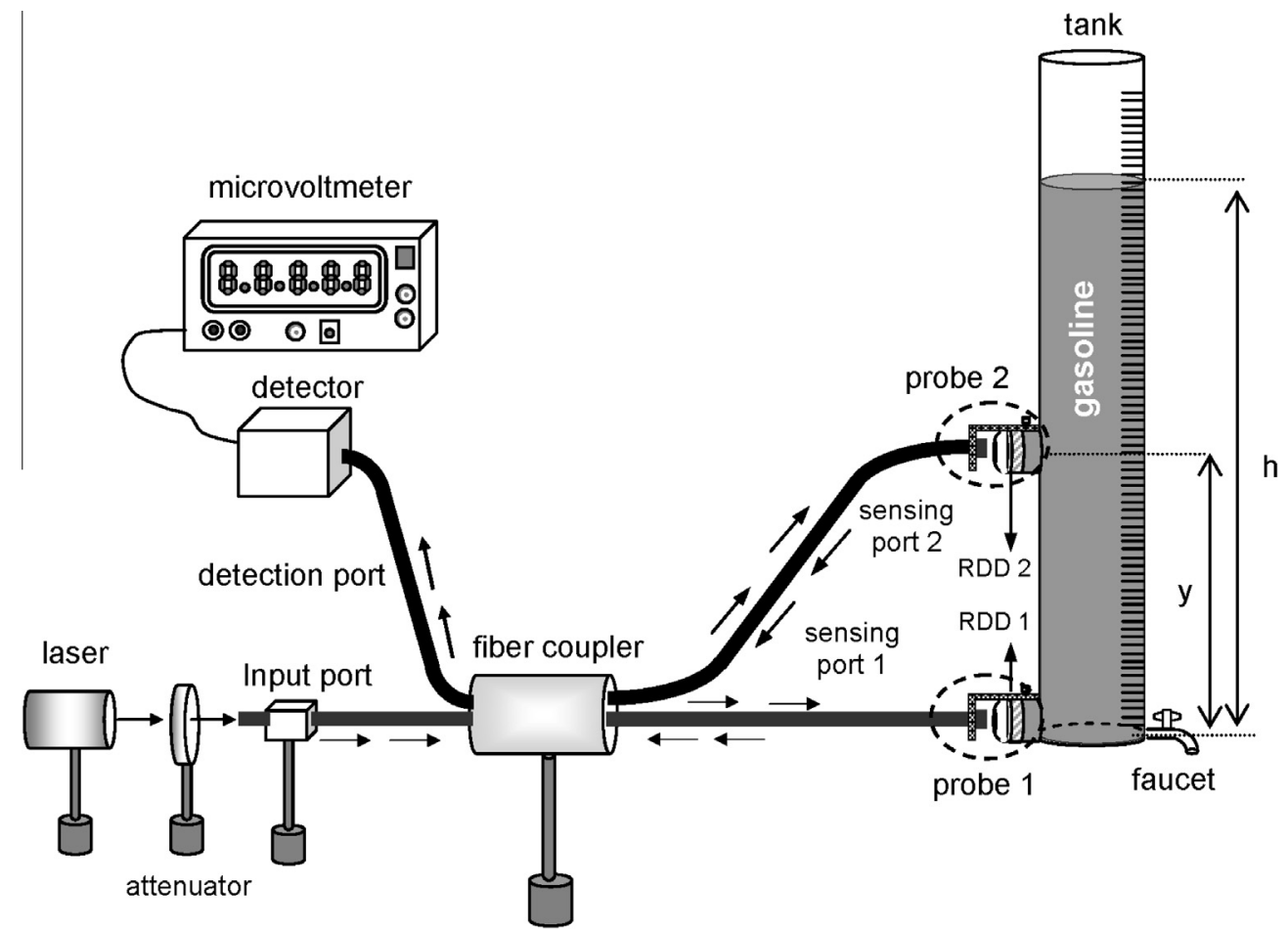

Fig. 2. Level sensor schematic diagram of gasoline using two probes. 

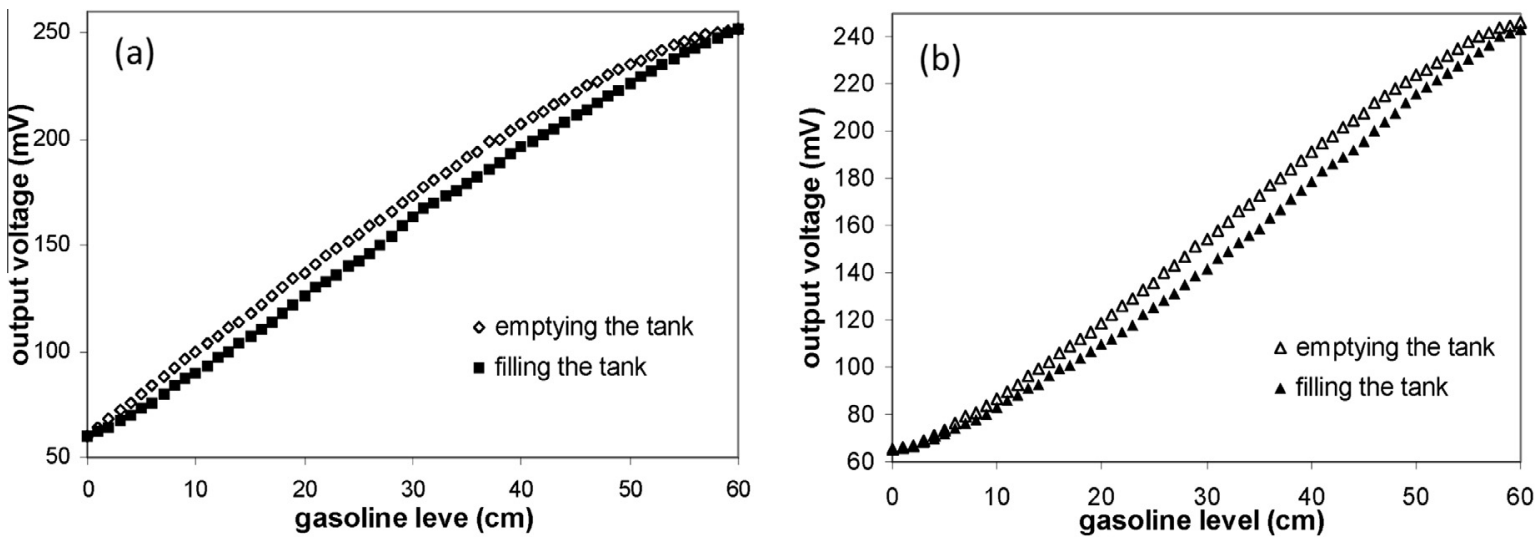

Fig. 3. Plot of output voltage detector to the gasoline level for (a) RDD A and (b) RDD B.
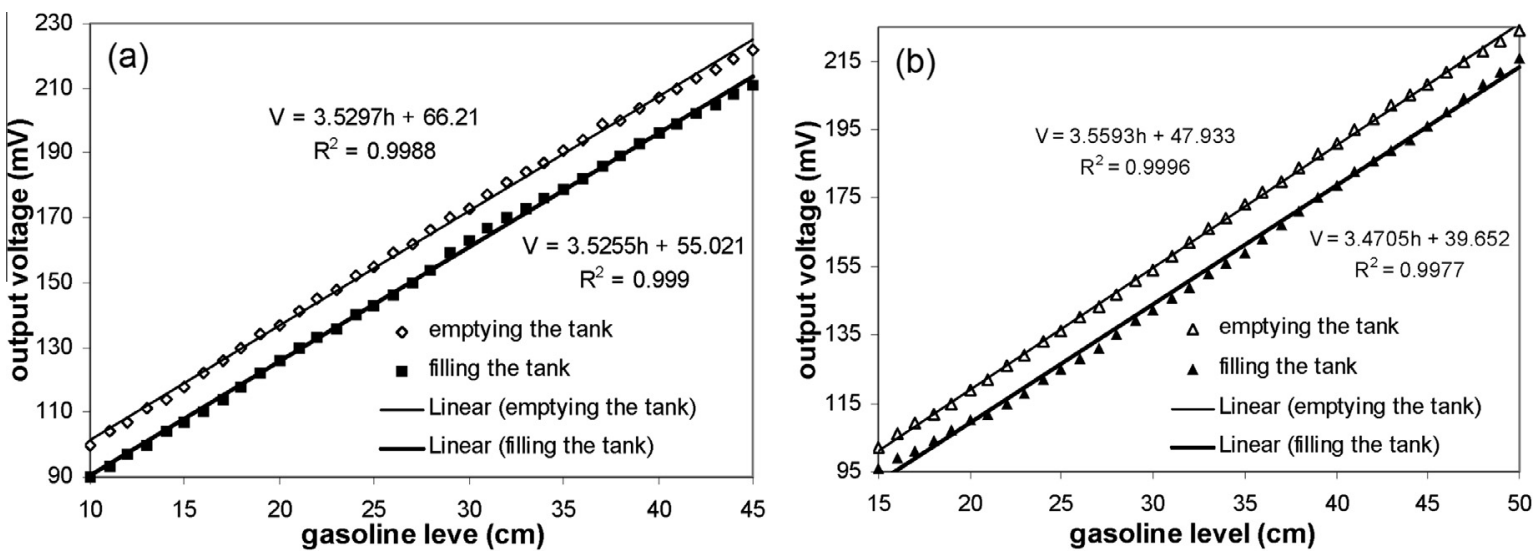

Fig. 4. The linear region of output voltage detector to gasoline level for (a) RDD A and (b) RDD B.

Table 1

The characteristics of gasoline using a single level sensor probe.

\begin{tabular}{llllll}
\hline Parameters & \multicolumn{2}{l}{$\begin{array}{l}\text { Emptying the } \\
\text { tank }\end{array}$} & & \multicolumn{2}{l}{ Filling the tank } \\
\cline { 2 - 3 } \cline { 5 - 6 } \cline { 5 - 6 } & RDD A & RDD B & & RDD A & RDD B \\
\hline Dynamic range $(\mathrm{cm})$ & 60 & 60 & & 60 & 60 \\
Linear region $(\mathrm{cm})$ & $10-45$ & $15-50$ & & $10-45$ & $15-50$ \\
Sensitivity $(\mathrm{mV} / \mathrm{cm})$ & 3.5 & 3.6 & & 3.5 & 3.5 \\
Resolution $(\mathrm{cm})$ & 0.3 & 0.3 & & 0.3 & 0.3 \\
\hline
\end{tabular}

by pairing the sensing port 1 with RDD 1 by face to face, while the second was formed by pairing the sensing port 2 with RDD 2 in face to face as well. Parameters $P_{i n}, P_{d}$, $P_{e 1}, P_{e 2}$ respectively are optical power of input light at the input port, output power at detection port, power emitted by the sensing port 1 and port 2 . Parameter $P_{b 1}$ and $P_{b 2}$ are optical power of the reflected light from reflectors RDD1 and RDD 2, which reflected back to the sensing port 1 , and sensing port 2 . RDD is a reflector, which attached to the membrane. This reflector will shift $\left(z^{\prime}\right)$ in case of hydrostatic pressure changes on the membrane as shown in Fig. 1(b).

The working principle of the sensor is detecting reflector shift against sensing port $(z)$ due to hydrostatic pressure of gasoline in the RDD. The changes in hydrostatic pressure occur due to changes of gasoline level. The shift in reflector will cause optical power changes in the reflected light from the reflector, which goes into sensing port fiber coupler $\left(P_{b}\right)$. The optical power changes will be observed through output voltage detector. Thus, the change in gasoline level will be detected through output voltage detector changes.

Probe 1 is used to detect the level of gasoline from the bottom of the tank to a certain level, for example $y_{2}$. This can be done by placing the sensing port 1 coincides with reflectors RDD 1 when gasoline reaches a level of $y_{2}$. Position of sensing port 1 is then made permanent. Change in gasoline level in $0-y_{2}$ will cause shifts in reflector RDD 1 $\left(z_{1}\right)$. As a result, the optical power of reflected light from the reflector RDD 1 to sensing port $1\left(P_{b 1}\right)$ is changed. Part of this change will be detected through the detection port. Optical power detected by probes 1 will be constant if the gasoline level exceeded $y_{2}$. Probe 2 is placed at a specific level above the position of the probe 1 , for example $y_{1}$. With the same mechanism as the probe 1 , probe 2 will detect the level of gasoline from $y_{1}$ to $y_{\max }$. When gasoline level reaches $y_{\max }$, sensing port 2 coincide with reflector RDD 2. Probe 2 will detect level of gasoline in term of 

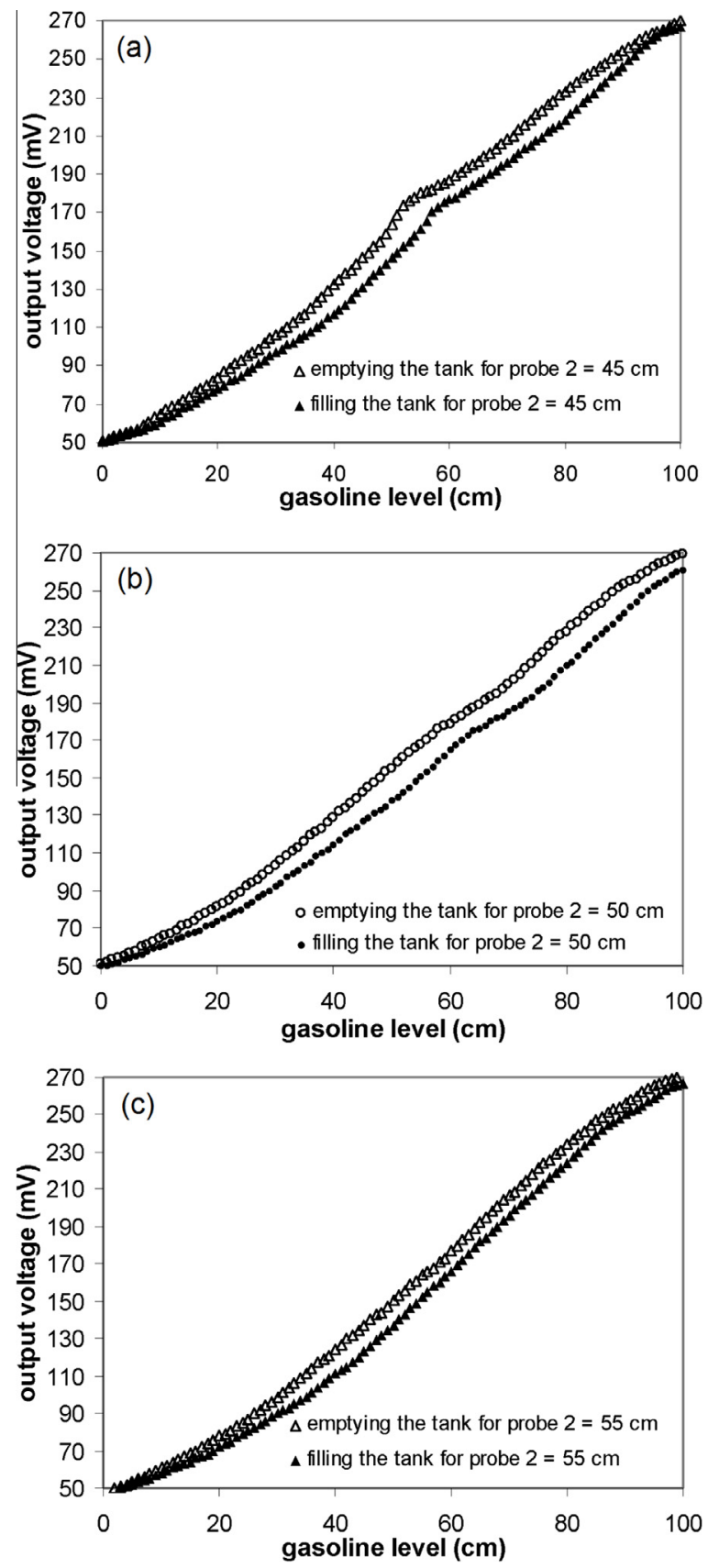

Fig. 5. Plot the data output voltage detector vs. gasoline level for emptying and filling process with position of probe 2 (a) $45 \mathrm{~cm}, 50 \mathrm{~cm}$ (b), (c) and $55 \mathrm{~cm}$ above probe 1 .

optical power changes which coming into the sensing port $2\left(P_{b 2}\right)$, then part of it is passed on to detection port of fiber coupler. Thus the detection of gasoline level from the bottom of tank to $y_{\max }$ carried through summation of optical power generated by probes 1 and 2 . Probe 2 can be placed on the detection upper limit of probe 1 i.e. $y_{2}$ or under $y_{2}$. If the location of the probe 2 is in $y_{2}$, the detection is done alternately by probe 1 (level: $0-y_{2}$ ) and probe 2 (level: $y_{1}-y_{\max }$ ). If probe 2 placed under $y_{2}$, then there is an area where the gasoline level $\left(y_{2}-y_{1}\right)$ is detected simultaneously by both probes.

The detection mechanism as described, then shift of reflector on the probe $1\left(z_{1}\right)$ occurred because of changes in the level of gasoline from 0 to $y_{2}$. If level range is denoted as $h_{1}$ then the pressure experienced by membrane in the RDD 1 can be written as:

$P_{h 1}=\rho g h_{1}$,

where $\rho$ and $g$ are gasoline density and gravitation acceleration respectively. Shifting the reflector $z_{1}$ due to the pressure $P_{h 1}$ was detected through optical power of output light at detection port $\left(P_{1 d}\right)$ and is written:

$P_{1 d}=P_{o}\left[1-\exp \left(-\frac{2}{\left(c z_{1}\left(h_{1}\right)+1\right)^{2}}\right)\right]$.

Relation between $z_{1}$ and $h_{1}$ in Eq. (2) has not been derived analytically [7]. Eq. (2) contains a provision $P_{0}=1.15 c r(1-c r)\left(10^{-0.1 L e}-10^{-0.1 D}\right)^{2} P_{\text {in }}$ and $c=(2$ tan $\left.\sin ^{-1} N A\right) / a$. Parameter $c r, L e, D, N A$, and $a$ are coupling ratio, excess loss, directivity, numerical aperture, and radius of fiber coupler respectively [8]. Eq. (2) emphasized that level detection in range $h_{1}$ is detected through $P_{1 d}$. Then for level of gasoline on the range of $y_{1}-y_{\max }$ here in after denoted $h_{2}$, will result in pressure on the membrane of the RDD 2 as:

$P_{h 2}=\rho g h_{2}$.

Pressure on the equation of (3) will result in a shift of the reflector on the probe 2 i.e. $z_{2}$. By the same mechanism, optical power output from detection port due to changes in the gasoline level $h_{2}$ (symbolized as $P_{2 d}$ ) can be written:

$P_{2 d}=P_{o}\left[1-\exp \left(-\frac{2}{\left(c z_{2}\left(h_{2}\right)+1\right)^{2}}\right)\right]$.

Detection of gasoline level in the range $0-y_{\max }$ is the sum of optical power of light generated by probes 1 and $2\left(P_{d}\right)$ and is written:

$P_{d}=P_{o}\left[2-\exp \left(-\frac{2}{\left(c z_{1}\left(h_{1}\right)+1\right)^{2}}\right)-\exp \left(-\frac{2}{\left(c z_{2}\left(h_{2}\right)+1\right)^{2}}\right)\right]$

Eq. (5) explains that the optical power output light at detection port is the sum of optical power of reflected light from reflector of probes 1 and 2 . The reference point of reflector shift is the position of each sensing port. If total gasoline level $\left(0-y_{\max }\right)$ is denoted as $h$, then the detection zone is divided into three areas. For gasoline level at range of $0 \leqslant h<y_{1}$, then $z_{2}$ is constant and Eq. (5) can be written as:

$P_{d}=P_{o}\left[2-\exp \left(-\frac{2}{\left(c z_{1}\left(h_{1}\right)+1\right)^{2}}\right)-\exp \left(-\frac{2}{\left(c z_{2}+1\right)^{2}}\right)\right]$.

Eq. (6) indicates that the third term is constant, it means that probe 2 has yet to detect the level of gasoline. For gasoline level at range of $y_{1} \leqslant h<y_{2}$, Eq. (5) can be written as: 

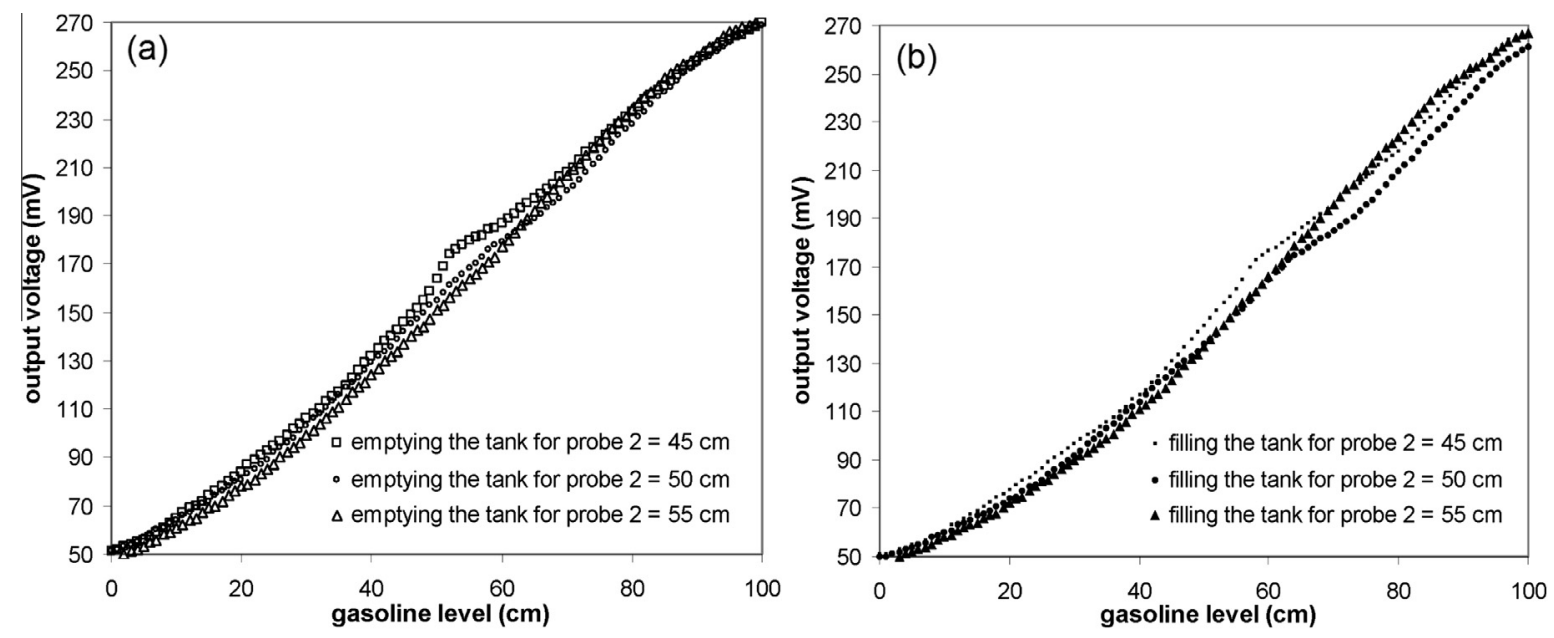

Fig. 6. Comparison chart data for probe 2 position of $45 \mathrm{~cm}, 50 \mathrm{~cm}$, and $55 \mathrm{~cm}$ above probe 1 in process of (a) emptying and (b) filling.

$P_{d}=P_{o}\left[2-\exp \left(-\frac{2}{\left(c z_{1}(h)+1\right)^{2}}\right)-\exp \left(-\frac{2}{\left(c z_{2}\left(h-y_{1}\right)+1\right)^{2}}\right)\right]$

Eq. (7) shows that both of probes detect the gasoline level simultaneously. If gasoline level at range of $y_{2} \leqslant h<h_{\max }$, then $z_{1}=0$ and Eq. (5) can be written as:

$P_{d}=P_{o}\left[2-\exp (-2)-\exp \left(-\frac{2}{\left(c z_{2}\left(h-y_{1}\right)+1\right)^{2}}\right)\right]$.

Eq. (8) indicates that the probe 2 stops detecting the level of gasoline.

In the case of the probe 2 is placed at position $y_{2}$ $\left(y_{1}=y_{2}\right)$, the detection zone is divided into two detection zones. For gasoline level is in the range of $0 \leqslant h<y_{2}$, Eq. (6) is applied and at a range of $y_{2} \leqslant h<h_{\max }$, Eq. (8) is applied instead with $y_{1}$ is replaced $y_{2}$. It means that both of the probe detect the level of gasoline interchangeably.

\section{Experiment}

Schematic diagram of the experiment is shown in Fig. 2. The experimental set-up consists of a laser semiconductor (with wavelength of $630 \mathrm{~nm}$ and output power of $10 \mathrm{~mW}$ ), attenuator, silicon photo detector, multimode fiber coupler with structure of $2 \times 2$ made of plastic (with a diameter of $1 \mathrm{~mm}, 1 \mathrm{~m}$ length, 50/50 split ratio, 3.7-5.6 dB insertion loss, and $1.6 \mathrm{~dB}$ excess for loss), microvoltmeter, cylindrical scaled gasoline tank which is made of glass (with $6 \mathrm{~cm}$ diameter and $100 \mathrm{~cm}$ length) and filled with gasoline $\left(715-780 \mathrm{~kg} / \mathrm{m}^{3}\right.$ density at $\left.15^{\circ} \mathrm{C}\right)$. In the bottom of gasoline tank, a faucet is used to remove the gasoline. Two of the RDD each consists of reflector which is made of aluminum (with $10 \mathrm{~mm}$ in diameter and $0.20 \mathrm{~mm}$ in thickness), single ply membrane (nitrile polymer) with thickness of $0.08 \mathrm{~mm}$ (the elastic modulus is not known), and cylindrical membrane holder which is made of brass with $18 \mathrm{~mm}$ outer diameter and inner diameter of $15 \mathrm{~mm}$. The reflector is attached to the membrane using epoxy glue and membrane itself behaves like a spring. Our RDD is handmade, because we made it manually using hand. An RDD is paired with a sensing port fiber coupler through holder form probe 1 . Sensing ports can be moved closer to or away from the reflector RDD. RDD and other sensing port paired to form probe 2 . Probe 1 is placed at the bottom of the tank. Probe 2 is connected through a pipe to the tank (the position of the probe 2 can be changed freely) and put on top of the probe 1 .

The first step of experiment is to conduct characterization of both RDD (called RDD A and RDD B) as gasoline level sensor using one probe (second probe is not used). This characterization is necessary because both of RDD were handmade so that there is a possibility that both of RDD have different characteristics. The characterization is done by putting RDD A at the bottom of the tank. After all devices are activated, the tank is filled slowly with gasoline using a manual pump. Maximum gasoline level given is $60 \mathrm{~cm}$. This is done because the range of the previous linear range of sensor is equal to $40 \mathrm{~cm}$ located in the maximum level, means that position of sensing port is close to the RDD. After gasoline reached levels of $60 \mathrm{~cm}$, position of sensing port 1 is made to coincide with reflector RDD A. Data for the emptying gasoline tank was obtained by recording the output voltage detector every gasoline level decrease by $1 \mathrm{~cm}$. Level of gasoline was lowered by removing the gasoline through the faucets. After the emptying process, RDD A was characterized for filling process. The recording of output voltage detector is done every level of gasoline increase by $1 \mathrm{~cm}$. The same procedure was done for RDD B characterization.

The results of the characterization of both the RDD A and RDD $B$ then used to determine the position and function of both the RDD as probe 1 or probe 2 . Data on the range and sensitivity of sensors using a single probe from characterization is used to determine position of each $\mathrm{RDD}$ and the position of the probe 2 . After the probe 1 and 2 probes as well as the position of the probe 2 is determined (e.g. $y$ ), then gasoline level sensor experiments carried out using two probes with probe placement refers to 

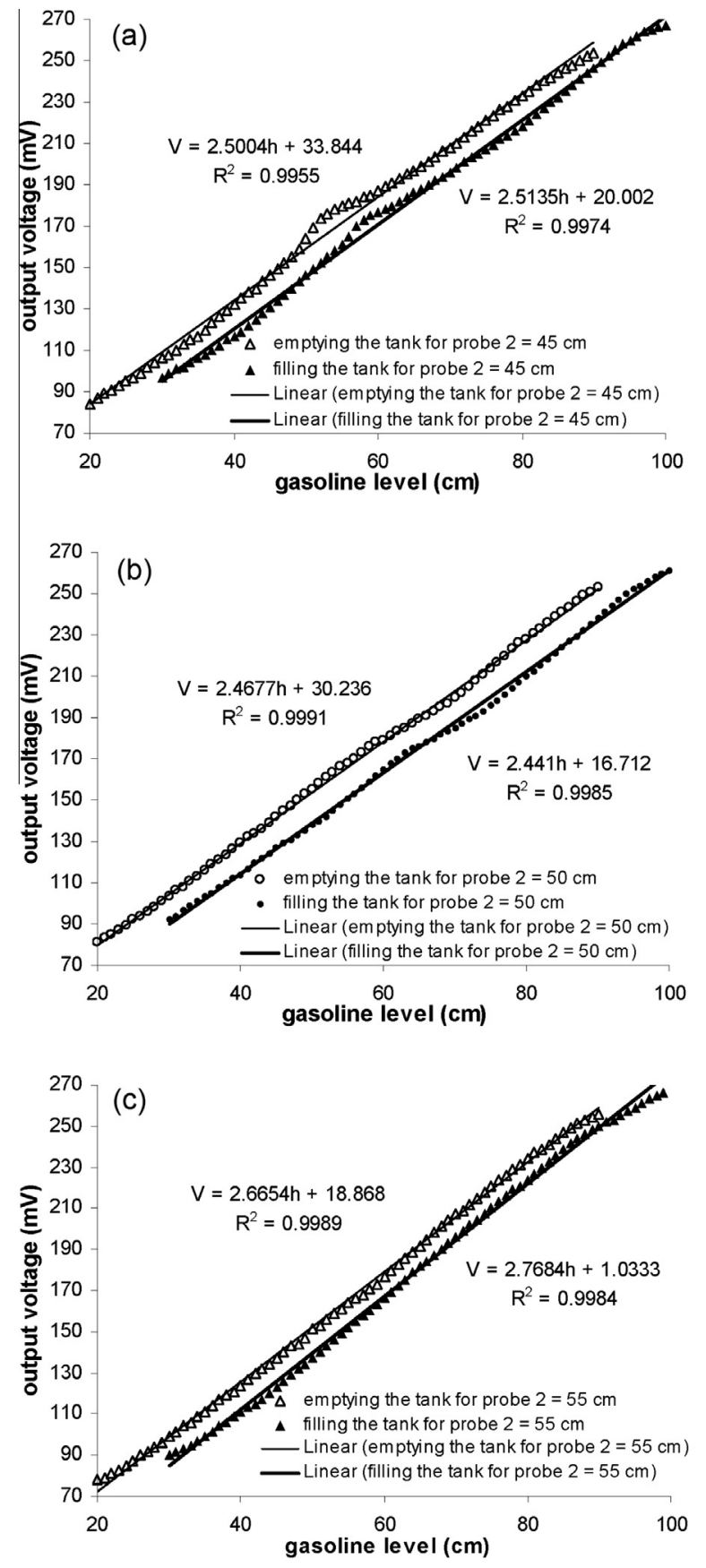

Fig. 7. Linear graph of the relationship between the output voltage detector to the level of gasoline for (a) position of the probe $2=45 \mathrm{~cm}$, (b) position of the probe $2=50 \mathrm{~cm}$, and (c) position of the probe $2=55 \mathrm{~cm}$.

Fig. 2. The next step is filling up the tank with gasoline. When gasoline reaches a level of $60 \mathrm{~cm}$, sensing ports 1 is placed coincide with reflector RDD 1. Filling of gasoline continued to reach maximum level $(100 \mathrm{~cm})$ and then sensing ports 2 is placed coincide with reflector RDD 2. Data retrieval for emptying gasoline tank was done by recording the output voltage detector every gasoline level decrease by $1 \mathrm{~cm}$. In process of filling the tank, the recording of output voltage detector is done every level of gasoline increase by $1 \mathrm{~cm}$. This procedure was done in the three different positions of the probe $2(y)$.

\section{Result and discussion}

Characterization of RDD A and RDD B as gasoline level sensor using a single probe produces data output voltage detector as a function of gasoline level for filling and emptying process. The plot of this data is shown in Fig. 3. While linear region of relation between output voltage detector with gasoline level is shown in Fig. 4.

As described in section experiment, maximum level of gasoline supplied (dynamic range using a single sensor probe) of $60 \mathrm{~cm}$ is based on the results obtained previously. In previous research, linear area of $40 \mathrm{~cm}$ (for RDD using single-ply membrane) occurs when the distance between sensing ports with reflector RDD is not too far or the level of gasoline isn't too large [7]. Fig. 3 shows that there is a difference between emptying and filling process (hysteresis). This occurs on both RDD A and RDD B. The difference between emptying and filling process is $6.1 \%$ for RDD A and 5.3\% in RDD B.

In this study, the main goal is to increase linear region (working range) of sensor by combining two sensors RDD and two sensing port fiber coupler as two probes. Both of these probes have function to detect the level of gasoline in multilevel way. Therefore, in RDD characterization as sensor using a single probe, wide dynamic range is not important. The range of linear region generated by RDD A and RDD B for emptying and filling process has an equivalent value of $35 \mathrm{~cm}$ (10-45 cm for RDD A and 15-50 cm for RDD B). For linear slope (sensor sensitivity), as shown in Fig. 4, RDD A and RDD B have small different for either filling or emptying process.

In this experiment, the devices only able to detect the smallest changes in gasoline level by $1 \mathrm{~cm}$.

The detection was observed in the output voltage detector of $1 \mathrm{mV}$ or $\Delta V=1 \mathrm{mV}$. If optical laser power is reduced, then the sensor is able to detect changes in gasoline level less than $1 \mathrm{~cm}$ or output voltage detector resulting in smaller than $1 \mathrm{mV}$, but the voltage is unstable. Conversely, if the laser power exceeds $10 \mathrm{~mW}$, then the level of the smallest detectable gasoline level is larger than $1 \mathrm{~cm}$. Value of $\Delta V$ produced divided by the value of the sensitivity of the sensor yields resolution of the sensor. Thus, the level sensor characteristics of gasoline using a probe with RDD A and $\mathrm{B}$ as probe are listed in Table 1 . Table 1 indicates that there are differences between RDD A and RDD B in sensitivity and linear range. The differences are due to both of RDDs are handmade so it has unique characteristics.

To reconstruct gasoline level sensor using two probes, slope of linear graph (sensor sensitivity) both of RDD as probe is primary consideration. Because the value of RDD A and RDD B slope difference is not too large, then both of RDD are suitable for use as probe, which will be arranged in cascade. The second consideration is an area outside the linear region. Region $0-10 \mathrm{~cm}$ and $45-60 \mathrm{~cm}$ for RDD A and 0-15 cm and 50-60 cm for RDD B in Fig. 3 is taken into consideration in determining the RDD A or 
Table 2

Characteristics of gasoline level sensor using two probes.

\begin{tabular}{|c|c|c|c|c|c|c|}
\hline \multirow[t]{2}{*}{ Parameters } & \multicolumn{3}{|c|}{ Emptying the tank with position probe 2} & \multicolumn{3}{|c|}{ Filling the tank with position probe 2} \\
\hline & $45 \mathrm{~cm}$ & $50 \mathrm{~cm}$ & $55 \mathrm{~cm}$ & $45 \mathrm{~cm}$ & $50 \mathrm{~cm}$ & $55 \mathrm{~cm}$ \\
\hline Dynamic range $(\mathrm{cm})$ & 100 & 100 & 100 & 100 & 100 & 100 \\
\hline Linear region $(\mathrm{cm})$ & $20-90$ & $30-100$ & $20-90$ & $30-100$ & $20-90$ & $30-100$ \\
\hline$R^{2}$ (goodness of fit) & 0.9955 & 0.9991 & 0.9989 & 0.9947 & 0,9985 & 0.9984 \\
\hline Sensitivity (mV/cm) & 2.5 & 2.5 & 2.7 & 2.5 & 2.4 & 2.8 \\
\hline Resolution $(\mathrm{cm})$ & 0.4 & 0.4 & 0.4 & 0.4 & 0.4 & 0.4 \\
\hline
\end{tabular}

Table 3

The comparison of performance between optical level sensors.

\begin{tabular}{llll}
\hline Method & $\begin{array}{l}\text { Dynamic } \\
\text { range }(\mathrm{m})\end{array}$ & $\begin{array}{l}\text { Linear } \\
\text { region }(\mathrm{m})\end{array}$ & $\begin{array}{l}\text { Resolution } \\
(\mathrm{cm})\end{array}$ \\
\hline $\begin{array}{l}\text { Spiral side-emitting } \\
\quad \text { optical fiber }\end{array}$ & 0.9 & - & 1 \\
$\begin{array}{l}\text { Long period fiber Bragg } \\
\quad \text { grating }\end{array}$ & 1 & - & 10 \\
$\begin{array}{l}\text { Fiber Bragg grating } \\
\text { Fiber interferometer } \\
\quad \text { using PCF }\end{array}$ & 0.36 & 0.4 & 6 \\
$\begin{array}{c}\text { One output port fiber } \\
\quad \text { coupler }\end{array}$ & 1.8 & 0.05 & - \\
$\begin{array}{c}\text { Two output port fiber } \\
\text { coupler (our paper) }\end{array}$ & 1 & 0.4 & 0.6 \\
\hline
\end{tabular}

RDD B as probe 1 . Based on the data obtained, then RDD A was selected as RDD 1 paired with sensing port 1, which serves as the probe 1 . While RDD B was selected as RDD 2 paired with sensing port 2 and serves as the probe 2 as shown in Fig. 2.

Gasoline level sensor experiments using two probes conducted by varying position of the probe 2 is as high as $45 \mathrm{~cm}, 50 \mathrm{~cm}$, and $55 \mathrm{~cm}$ from the probe 1 . Experimental results are in the form of output voltage detector as a function of gasoline level for emptying and filling the tank process. The results are shown in Fig. 5. In this experiment, the laser power used is scaled down using the attenuator as shown in Fig. 2. The use of two sensing port fiber coupler optical power increasing repercussions on the received light detector especially when the gasoline level reaches maximum level. Increasing the optical power caused the sensor does not detect changes in the gasoline level of $1 \mathrm{~cm}$, but more than $1 \mathrm{~cm}$. Hence, at maximum level (output voltage detector at the maximum state), maximum output voltage difference only ranges of $20 \mathrm{mV}$. When the tank is empty, the output voltage detectors made almost the same as when using a single sensor probe experiment. Data on the process of emptying the tank does not equal with the data on the process of filling the tank. The average difference is $6.5 \%, 8.1 \%$, and $6.0 \%$ respectively for probe 2 position of $45 \mathrm{~cm}, 50 \mathrm{~cm}$, and $55 \mathrm{~cm}$. The comparative plot of the both data (emptying and filling process) for all positions of probe 2 is shown in Fig. 6. Fig. 6 (a) is for emptying process while filling process is shown in Fig. 6(b). For a graph of the linear relationship between the output voltage detectors to gasoline level for all positions of the probe 2, which is as high as $45 \mathrm{~cm}, 50 \mathrm{~cm}$, and $55 \mathrm{~cm}$ from the probe 1, is shown in Fig. 7 .

Comparison of gasoline level sensor characteristics using two probes with the position of probe 2 is at varying position is shown in Table 2 . Table 2 shows the linear range of gasoline level sensor using two probes is $70 \mathrm{~cm}$, which is twice in comparison with linear range of the sensor using a single probe (linear range at $35 \mathrm{~cm}$ ). In other hand, sensitivity and resolution of the sensor using two probes are smaller than the sensor using a single probe. Smaller sensitivity occurs due to laser power reduction in experiment of gasoline level sensor using two probes.

Based on results of gasoline level sensor using two probes as shown in Table 2, almost no parameters showed significantly different values, except the value of sensitivity. From three positions of probe 2, gasoline level sensor with position of probe 2 at $55 \mathrm{~cm}$ showed the best performance because it had higher sensitivity value (an average of $2.75 \mathrm{mV} / \mathrm{cm}$ ) than other positions. Thus the use of two sensing port fiber coupler as a component of two probes capable to increase linear range or working area of the gasoline level sensor. A study of the linear range of gasoline level sensor is very important because analytical formulation of gasoline level sensor transfer (Eq. (5)) is not complete yet. With linear range or working area of $70 \mathrm{~cm}$, then gasoline level sensor prototype from this experiment is suitable as sensor level of gasoline or other fuels in industries that require fuel level sensor is secure from explosion or fire.

Table 3 shows the comparison of performance between our level sensors with other optical level sensor. The advantages of our sensor level compared to the other level sensor as shown in Table 3 is larger linear region and smaller resolution.

\section{Conclusions}

The use of two channel output fiber coupler structure of $2 \times 2$ as two probes to detect the level of gasoline are capable of producing a linear range or working area two times wider than the use of single probe. Gasoline level sensor using two probes with the position of the probe 2 at $55 \mathrm{~cm}$ above probe 1 is able to detect the level of gasoline with the dynamic range, the linear region, and resolution are $100 \mathrm{~cm}, 70 \mathrm{~cm}$, and $0.4 \mathrm{~cm}$ respectively for emptying and filling the tank process. Sensor sensitivity value for filling and emptying of the tank process is $2.7 \mathrm{mV} / \mathrm{cm}$ and $2.8 \mathrm{mV} / \mathrm{cm}$ respectively.

\section{References}

[1] M. Lomer, J. Arrue, C. Jauregui, P. Aiestaran, J. Zubia, J.M. LopezHiguera, Lateral polishing of bends in plastic optical fibres applied to a multipoint liquid-level measurement sensor, Sens. Actuators A 137 (2007) 68-73. 
[2] Chengrui Zhao, Lin Ye, Yu Xun, Junfeng Ge, Continuous fuel level sensor based on spiral side-emitting optical fiber, J. Control Sci. Eng. 2012 (2012) 1-8.

[3] Jian-Neng Wang, Ching-Ying Luo, Long-period fiber grating sensors for the measurement of liquid level and fluid-flow velocity, Sensors 12 (2012) 4578-4593.

[4] Hossein Golnabi, Design and operation of a fiber optic sensor for liquid level detection, Opt. Lasers Eng. 41 (2004) 801-812.

[5] Kyung-Rak Sohn, Joon-Hwan Shim, Liquid-level monitoring sensor systems using fiber Bragg grating embedded in cantilever, Sens. Actuators A 152 (2009) 248-251.
[6] Xinpu Zhang, Wei Peng, Zigeng Liu, Zhenfeng Gong, Fiber optic liquid level sensor based on integration of lever principle and optical interferometry, IEEE Photon. 6 (2) (2014) 6801108.

[7] Samian, G.Y.Y. Yhosep, A.H. Zaidan, Herlik Wibowo, Gasoline level sensor based on displacement sensor using fiber coupler, Measurement 58 (2014) 342-348.

[8] A. Samian, Yono Hadi Pramono, Ali Yunus Rohedi, Febdian Rusydi, A. H. Zaidan, Theoretical and experimental study of fiber-optic displacement sensor using multimode fiber coupler, J. Optoelectron. Adv. Mater. - Rapid Commun. 3 (5) (May 2009) 411-414. 